\title{
¿Quo vadis, Argentina?
}

\author{
CARLOS ALTAMIRANO
}

CC $\begin{aligned} & \text { A ARgentina es como un pantano: nos hundimos, pero nunca se } \\ & \text { toca fondo". Hasta comienzos de diciembre del año pasado, éste } \\ & \text { era uno de los tantos sarcasmos que los argentinos se dedicaban a sí }\end{aligned}$ mismos, entre angustiados e impacientes por una caída que parecía no tener término. ¿Qué cabía esperar sino tocar el fondo después de tres años de recesión, de los recortes de salarios y jubilaciones, una desocupación superior al 20 por ciento, la insolvencia del Estado, la caída constante del consumo y una pobreza que no hacía sino aumentar? Mientras los signos del hundimiento se multiplicaban, los políticos oficialistas y los de la principal fuerza de oposición, como si sólo quisieran añadir pruebas de su irresponsabilidad, ofrecían únicamente el espectáculo diario de sus reyertas, atribuyéndose mutuamente el origen de los problemas y maniobrando para que el rival no sacara ventajas de las dificultades. Cuando, finalmente, el derrumbe se produjo, quedó a la vista de todos la magnitud de la brecha que se había abierto entre el pais real y el pais formal, para decirlo en el lenguaje de los nacionalistas maurrasianos.

Desde entonces, si hay un sentimiento generalizado entre los argentinos, que iguala a quienes están en el gobierno con quienes reclaman, en manifestaciones masivas, que se vayan todos los políticos, es el de la ansiedad por un porvenir que aparece indeciso. Hay, por cierto, interpretaciones diferentes respecto de la crisis y sus causas, aunque todas coinciden en que ella es general y profunda. Es frecuente también leer y oír hablar, incluso desde antes del derrumbe, del fin de una época o de un régimen, sea para referirse a los años noventa, la corrupción y su figura emblemática, Carlos Menem; al sistema político fundado en la sociedad de los dos partidos - el peronismo y el radicalismo -; al dominio incontrastado del neoliberalismo, o bien a todos estos hechos. Más indefinido es lo que se dice sobre lo que sobrevendrá después del fin. "El futuro es un cristal turbio": difícilmente pueda hallarse una frase más elocuente que ésta, recogida en una de las tantas asambleas de barrios que pululan hoy en Buenos Aires (1). Es que la crisis que atormenta a la Argentina es tan compleja y con algunos aspectos tan nuevos que nadie puede estar seguro de comprender enteramente el sentido del proceso que está en curso. Los pronósticos sobre el fin de los partidos tradicionales, que es frecuente leer en estos días, o sobre la regeneración de la democracia que traerá aparejada la movilización de las clases medias, o las advertencias sobre la fragmentación y los riesgos de disolución en una "guerra de todos contra todos", no son posibilidades que puedan, simplemente, descartarse. Al mismo tiempo, es innegable que esos pronósticos no transmiten sólo hipótesis sino también deseos y temores. 
Este cuadro de expectativas e incertidumbre obra sobre cualquier enfoque que pueda hacerse de la situación argentina actual y a ese condicionamiento no escapa, obviamente, la perspectiva que ofrecemos en las páginas que siguen. El centro en torno al cual gira el artículo es esa rebelión de las masas de clase(s) media(s) que ha puesto en jaque a los partidos y a la democracia representativa en el país. Fenómeno de repercusión mundial, constituye uno de los hechos nuevos de la crisis y, sin dudas, el que ha despertado mayores interrogantes y conjeturas entre los propios argentinos. Lo que nos proponemos es discurrir alrededor de ese hecho, ligando su descripción a las condiciones que lo hicieron posible aunque no obligado.

\section{¿Qué es esto?}

¿Cuál es el significado y qué cabe esperar del movimiento que reúne hoy a vecinos y militantes, novatos y curtidos, en asambleas de barrios y marchas donde se reclama el fin del "corralito", el alejamiento de los dirigentes políticos y la renuncia de la Corte Suprema de Justicia? Evoquemos brevemente el encadenamiento inicial del proceso por el cual una parte del poder en la Argentina ha terminado instalándose en las calles.

La primera manifestación colectiva de protesta por medio del cacerolazo, las bocinas de los autos y el oscurecimiento de las vidrieras de los comercios tuvo lugar el 12 de diciembre. Había sido convocada dos días antes por comerciantes, industriales pequeños y entidades de defensa del consumidor, en repudio a las medidas económicas del gobierno de Fernando de la Rúa, en primer lugar contra las restricciones al uso de los depósitos por parte de sus titulares y la bancarización obligatoria de todos los pagos superiores a mil pesos. La protesta, que tuvo su foco en Buenos Aires, extendió a toda la ciudad los redobles de cacerolas y los bocinazos, pero fue en los barrios donde, a partir de las 8 de la noche, comerciantes y vecinos se reunieron espontáneamente en las esquinas para sacar el reclamo a las calles. Una semana después estallaron los saqueos de comercios y supermercados en en las barriadas pobres del Gran Buenos Aires, alentados por dirigentes del peronismo, según es hoy vox populi. La alocución en que el presidente de la Rúa comunicó el establecimiento del estado de sitio para hacer frente a la situación, que había dejado un saldo de muchos muertos, provocó otro cacerolazo nocturno, más fuerte que el anterior, y una manifestación masiva de ciudadanos, que marcharon hacia la Plaza de Mayo, la Plaza de los Dos Congresos y el Obelisco, reclamando la dimisión de Domingo Cavallo y algo más, como subrayaría el diario Clarín: “¿Que se vayan!”, en plural (2).

La concentración congregada en la Plaza de Mayo terminó, en la madrugada del día siguiente, con una bárbara represión policial que provocó la muerte de 5 manifestantes. Para esas horas el ministro Cavallo ya había renunciado y poco después lo seguiría el propio presidente. Desde ese miércoles 19 de diciembre la movilización se hizo permanente, contagiándose aceleradamente a 
otras ciudades del país. La liquidación del gobierno de Rodríguez Saá, acelerada por la lucha intestina del peronismo, pero antecedida por un vasto cacerolazo, mostró con la claridad más didáctica que ningún órgano del Estado, sea nacional, provincial o municipal, podía ignorar el establecimiento de ese nuevo humor público. Para entonces, la consigna “iQue se vayan todos”! indicaba que la condena se había generalizado al conjunto de los políticos.

En un comienzo, el epicentro de esta revuelta cívica fueron los barrios característicos de las clases medias de Buenos Aires (Palermo, Caballito, Almagro) y aun zonas habitadas por sectores más acomodados, como Belgrano y Barrio Norte. Estos fueron en diciembre los focos de los cacerolazos, y la mayor parte de los contingentes que se agrupaban para marchar hacia el centro de la ciudad en columnas formadas por familias, jóvenes, jubilados, provenían de dichos barrios. Todavía hoy, cuando el movimiento se ha ampliado, las clases medias constituyen su columna central.

No es necesario insistir aquí sobre la polisemia que caracteriza al término “clases medias". Digamos, simplemente, que la Argentina no es una excepción en este terreno y lo que se indica con esa noción, en el lenguaje de las ciencias sociales no menos que en el lenguaje corriente, está lejos de ser un universo social homogéneo. Como en otras partes, lo que se reúne bajo la categoría de clases medias es un conglomerado de grupos y sectores urbanos que no pueden clasificarse ni entre los obreros, ni entre los grandes patrones y propietarios. Algunos de ellos son trabajadores autónomos (comerciantes chicos, dueños de pequeños talleres, profesionales liberales), otros, la mayoría, asalariados (cuadros y técnicos de la administración estatal, empleados de los servicios públicos y privados, docentes de los diferentes niveles del sistema educativo) (3). No es, pues, la ocupación ni la categoría socio-profesional lo que este conjunto tiene en común, sino más bien, como lo suele registrar la intuición práctica respecto de la "clase media", ciertos rasgos relativos a los modos de comportamiento, los lugares de residencia, la valorización de la educación y la propensión al moralismo. Estas observaciones, así apuntadas, hacen pensar en una clase media intemporal, cuando, en realidad, ese universo social se transformó profundamente a lo largo del siglo XX, en la Argentina al igual que en otras partes. Pero los cambios no fueron sólo sociales: también su comportamiento político conocería variaciones importantes.

\section{El periplo de las clases medias}

Acaso ningún otro sector ilustra como éste las curvas del "progreso argentino". Su expansión fue el parámetro de la movilidad social ascendente ya en las primeras décadas del siglo pasado (4); bajo el primer peronismo, el crecimiento de sus contingentes, sobre todo el de las categorías asalariadas del conglomerado, es más rápido que el crecimiento de las filas obreras; y la dilatación continuó en los años de la modernización desarrollista, en los sesenta (5). En 
1980 el colectivo de las clases medias representaba el $47 \%$ de la fuerza de trabajo total. Este no sólo fue un universo social en expansión en los tres cuartos del siglo XX, sino que su composición interna se modificó profundamente a lo largo de ese trayecto y cada vez sería mayor en sus filas el volumen de los asalariados. Lo que estos cambios no alteraron fue la certidumbre de la movilidad social, convertida en sentido común.

Las clases medias urbanas estuvieron lejos de ser políticamente pasivas y la disposición (al menos la de algunas de sus fracciones) para la movilización ideológica y política inspiraría la boutade de que en la Argentina la única clase revolucionaria no era el proletariado, sino la clase media. Entre 1945 y 1946 y, nuevamente, entre 1954 y 1955, le proporcionó respaldo y su único movimiento de masas - el movimiento universitario - a la coalición social y política que enfrentó a Perón y al régimen justicialista. Después del derrocamiento de Perón, el apoyo a Arturo Frondizi y su llamado a unir al pueblo y la nación en la lucha por la Argentina industrial y el desarrollo provino asismismo de las clases medias. Una parte de los jóvenes de este sector, desandando poco a poco el camino antiperonista recorrido por los adultos de su clase, se convirtió a una versión radical del peronismo (interpretado como el movimiento de liberación nacional in nuce) y le proporcionó militantes, ideólogos y combatientes a los partidos armados de los años setenta. Como olas sucesivas de la activación política de las clases medias han de verse también el apogeo del alfonsinismo en los ochenta y el del Frepaso en la década siguiente, el primero con su foco en la cuestión democrática y el segundo en la denuncia de la corrupción política. En realidad, la fobia actual contra los políticos no puede comprenderse enteramente sin referencia a la expectativa y la decepción que significó el fruto que produjo el encuentro del alfonsinismo y el Frepaso, es decir, la Alianza y el gobierno de Fernando de la Rúa.

Pero antes de detenernos en este punto, consignemos brevemente los cambios que experimentó la situación de las clases medias en los últimos quince años y que habían de provocar la fragmentación de sus filas. A comienzos de los noventa se forjaron, en el campo de los estudios sociales en la Argentina, las nociones de "nueva pobreza" y "nuevos pobres" para registrar y describir el proceso de pauperización que tenía como víctimas a fragmentos cada vez más amplios de la clase obrera y las clases medias. El estancamiento económico de los ochenta y el modelo capitalista neoliberal adoptado en los noventa, que produjeron una brutal reclasificación económica y social, precipitarían a grandes contingentes de los sectores medios en el universo de la penuria (6). La caída de los ingresos, o la desocupación, y el deterioro de los servicios públicos en el terreno de la salud y la educación, se sumarían para contrariar lo que había constituido hasta entonces una suerte de sentido común de clase, la experiencia de la movilidad social ascendente. Así, muchos grupos, entre autónomos y asalariados de clase media, harían la experiencia inversa, la del descenso, incorpo- 
rándose al campo de los 'perdedores' con el sentimiento de la pérdida y la frustración.

Desde mediados de la década pasada, el fin de la clase media se convirtió en un tópico del discurso público. Pero, en verdad, no todos sus integrantes conocieron la suerte de la pauperización y las tribulaciones de la declinación social. Recordemos el éxito que acompañó inicialmente al plan de estabilidad puesto en marcha por Domingo Cavallo en 1991, sobre el esquema de la paridad peso-dólar. La estabilidad que introdujo el Plan de Convertibilidad - que no sólo mejoró el poder de compra de las remuneraciones, sino que reabrió el crédito al consumo - y, seguidamente, el conjunto de medidas destinadas a desregular la economía, retirar al Estado de la producción privatizando sus empresas y abrir el mercado a la competencia externa, activaron el crecimiento económico y dinamizaron el consumo. Este auge, que descansaba fundamentalmente en el ingreso de capitales del exterior y cuya fragilidad se dejaría ver claramente después de la crisis mexicana, prosiguió, aunque sin el brío del comienzo, hasta 1998, cuando comenzó la larga recesión en que vive aún hoy el país. Mientras duró, ese efecto de riqueza - que no fue general, pues el aumento de la desocupación y la pobreza eran su contracara sombría - contó entre sus beneficiarios a franjas no insignificantes de las clases medias, que mejoraron sus ingresos, accedieron a la vivienda propia o se mudaron a una más costosa, renovaron sus automóviles, viajaron al exterior y, en fin, sofisticaron sus hábitos de consumo. La adopción del capitalismo neoliberal no tuvo, pues, efectos parejos sobre este conglomerado, algunos de cuyos segmentos se incorporaron al campo de los llamados "ganadores" del modelo. Lo cierto es, igualmente, que el "progreso" había dejado de ser una experiencia colectiva.

\section{La ilusión de la Alianza}

Estos cambios no se proyectaron de manera significativa en los alineamientos políticos de la década del noventa. La clara mayoría política que construyó Carlos Menem entre 1991 y 1995 recibió apoyo de las clases medias, sobre todo en el interior del país. La base principal de su poderío, sin embargo, no radicó allí sino en el voto de las clases populares, históricamente peronistas, y en el caudal, más inestable, que le proporcionó el apoyo de la derecha social y política, a la que atrajo mediante su pragmática conversión al neoliberalismo. Aunque el campo de la oposición política al menemismo tuvo igualmente una composición interclasista, su columna vertebral fueron las clases medias de las grandes ciudades. De éstas extraerían respaldo y la mayor parte de sus votos no sólo, como era ya un dato histórico, el radicalismo y los pequeños partidos de izquierda, sino también el Frepaso, cuyo fulgurante surgimiento fue uno de los fenómenos políticos de la década. En otras palabras: si bien a lo largo de los noventa las clases medias dispersaron sus simpatías y sus votos entre todas las formaciones políticas en presencia, la proporción de esa dispersión fue desigual 
y, en términos globales, favorable a las fuerzas de oposición en los principales distritos urbanos.

Podemos retomar ahora la cuestión de la Alianza, cuyo gobierno caería tan estrepitosamente en diciembre del 2001. Esta se constituyó en 1997 y sus signatarios fueron la Unión Cívica Radical y el Frepaso, un agrupamiento cuya aparición había alterado el juego político entre peronistas y radicales existente hasta 1994. ¿Qué era el Frepaso? Su núcleo original y su principal figura, Carlos "Chacho" Alvarez, procedían del peronismo, donde habían constituido, con ocho diputados, un polo disidente que concluiría por romper no sólo con la orientación menemista, sino con el partido peronista, visto como irredimiblemente corrupto. Identificados con las posiciones del populismo de izquierda, Alvarez y su grupo hicieron su primer ensayo electoral en 1993, asociados en el Frente Grande con social-cristianos y comunistas. La elección le dio el $13,4 \%$ de los votos en el distrito de la ciudad de Buenos Aires, resultado sorprendentemente bueno para una fuerza nueva. En las elecciones del año siguiente, celebradas para designar delegados a la asamblea destinada a la reforma de la Constitución, el Frente Grande casi triplicó sus votos en Buenos Aires (36\%) y obtuvo el $12 \%$ a nivel nacional, dejando ver que se había establecido un tercer actor en la escena.

Político repentista, imaginativo y carismático, "Chacho" Alvarez se destacó enseguida por sobre el resto de sus compañeros frentistas. Con una cultura intelectual mayor a la que es habitual entre los políticos argentinos, pero sin interés en la adopción ni en la formulación de definiciones ideológicas demasiado precisas, se desprendió rápidamente de sus aliados comunistas y se lanzó a la tarea de impulsar una coalición capaz de batir electoralmente a Menem. El primer fruto de esa iniciativa sería el Frepaso, una liga de grupos peronistas, social-cristianos y socialistas, que tuvo un excelente desempeño en los comicios de 1995, cuando Menem fue reelecto. Aunque esta coalición entró en crisis inmediatamente después de las elecciones, el trastorno de la alianza original fortaleció el liderazgo de Alvarez, quien recibió el apoyo de la mayoría de los grupos. ¿Cuál era la identidad del Frepaso, más allá del reconocimiento a la autoridad política de Alvarez? Programáticamente e ideológicamente vago, lo que el Frepaso exponía, en primer lugar a través de su líder, era una impugnación del menemismo fundada en lo que podríamos llamar una interpretación moral de la experiencia iniciada en 1989. La corrupción, que tenía como cabeza a Carlos Menem, aparecía como el punto donde todo se anudaba y, a la vez, todo cobraba sentido, desde las privatizaciones de empresas públicas al acatamiento que el partido peronista daba a un gobierno que había abandonado la tradición del peronismo. El otro tópico del discurso de Alvarez era el llamamiento y la promesa de una nueva política, más transparente y próxima los ciudadanos corrientes - la "gente". Esta promesa tenía como fondo la denuncia de su antítesis, la vieja política, ejercida por quienes sólo se servían de los 
cargos para defender intereses particulares o de partido, una política cuyo mecanismo era la transacción permanente. La censura de esta práctica no excluía a los radicales, señalados como miembros del mismo régimen, el "bipartidismo", al menos mientras el Frepaso rivalizó con ellos por la representación de la oposición a Menem.

Este mensaje - denuncia del menemismo como sistema corrupto que no había dejado a salvo ninguno de los poderes del Estado, reclamo de transparencia en la vida política, proximidad con la "gente" - se ajustaba variadamente con el populismo de izquierda que seguía constituyendo el repertorio ideológico básico de la cúpula del Frepaso, aunque ya no pareciera ser la de su líder. Pero Alvarez era quien estaba en comunicación con la "gente", sobre todo a través de la radio y la TV, que a partir de 1993 lo tendrían entre sus políticos predilectos. Esos medios le dieron gran audiencia a los tópicos de su proceso al menemismo y le ganaron la adhesión de franjas cada vez más amplias de los sectores progresistas de las clases medias, atraídas por su combate contra Menem y el llamado a una suerte de regeneracionismo cívico. El primer esbozo de la alianza que habrá de vencer al peronismo en las elecciones en 1999 fue el llamado que lanzó el Frepaso, y contó con el apoyo de los círculos radicales interesados en la coalición, a expresar públicamente un repudio al gobierno menemista. Los medios de expresión de la protesta que se llevó a cabo el 12 de septiembre de 1996 y tuvo su epicentro en los barrios de clase media de Buenos Aires, reaparecerán en diciembre del 2001: el apagón y los cacerolazos.

La Unión Cívica Radical aceptó constituir la alianza cuando sus dirigentes percibieron que una nueva y probable derrota electoral podía llevarlos a la irrelevancia política y la declinación definitiva. El sector progresista del radicalismo, entre socialdemócrata y populista, identificado con Raúl Alfonsín, tenía la mayoría del partido pero ninguna figura en condiciones de rivalizar con el peronismo en una elección presidencial. Por el contrario, Fernando de la Rúa, intendente de la ciudad de Buenos Aires, que representaba el alma liberal-conservadora del partido, sobrepasaba a todos los politicos en las encuestas de imagen, aunque estaba en minoría entre los radicales. Como la idea de poner en marcha el frente antimenemista dominará sobre cualquier otra entre los integrantes del acuerdo, de la Rúa será el candidato a presidente de los radicales $\mathrm{y}$, tras derrotar en una competencia interna a la aspirante del Frepaso, encabezará la fórmula presidencial de la alianza, acompañado por "Chacho" Alvarez como candidato a vice-presidente. Para entonces ninguna cuestión que no fuera la relativa a la estrategia electoral interesaba ya a los socios de la Alianza por el Trabajo, la Educación y la Justicia - el día después...vendría después.

La fórmula parecía reunir las cualidades contradictorias del orden y el movimiento: si de la Rúa atraía los votos de la clase media moderada y conservadora, no sólo en las grandes ciudades, sino en el conjunto del país, garanti- 
zando con su estilo y su propia carrera politica que no habría otros cambios que los propios de una gestión más austera, Alvarez aparecía como el fiador del carácter progresista del proyecto, aunque en verdad no se había comprometido sino con una innovación de tipo ético-político. Quien fue elegido por la cúpula de la coalición ya antes de las elecciones como futuro titular del Ministerio de Economía, José Luis Machinea, se encargó de transmitir al establishment local e internacional que una eventual gestión de la Alianza iba a respetar los parámetros del modelo capitalista que regía desde 1991, en primer término su premisa cambiaria (un peso=un dólar) y la reducción del déficit fiscal. En cuanto a la política social, los responsables de la Alianza confiaban, antes que nada, en las posibilidades de otra administración - esto es, sin corruptelas - de los recursos ya existentes. Todo lo demás descansaba en la hipótesis de una reactivación económica ya cercana.

\section{“QQue se vayan todos! ¡Que no quede ninguno!”}

Le hemos dado cierto espacio a estos datos relativos al Frepaso y la formación de la Alianza porque ayudan a comprender, al menos en parte, la mezcla de frustración y rabia antipolítica que se volcó a las calles en diciembre y aun hoy aflora en las asambleas barriales. No vamos a detenernos en la presidencia de Fernando de la Rúa, ni en su estilo de gobierno, basado en la indecisión permanente, ni en el inclasificable grupo que constituyó su entourage, ni en cómo avanzó hacia el descarrilamiento final, un desenlace que desde marzo del 2001 se volvió cada día más previsible. Sólo consignemos que la reactivación esperada por el equipo de Machinea no tuvo lugar y que Domingo Cavallo, vuelto al Ministerio de Economía en marzo del 2001, no fue más afortunado. Ninguno pudo poner fin a la recesión y sus secuelas - el aumento de la desocupación y la pobreza -; la caída de la recaudación tributaria impulsó nuevos impuestos y el ajuste fiscal se volvió permanente. Mientras tanto la Alianza se fue astillando. Pero, hay que subrayarlo, mientras ella duró -digamos, hasta la renuncia de Alvarez- los funcionarios de la nueva administración, sean radicales o frepasistas, no se mostraron en general más eficientes que sus antecesores ni siempre menos reprochables éticamente.

La nueva política, en otras palabras, se parecía demasiado a la vieja. No afirmó otra cosa Alvarez al renunciar al cargo de vicepresidente el 6 de octubre del 2000, "para poder decir con libertad lo que siento y lo que pienso y, al mismo tiempo, para no perjudicar al Presidente ni alterar el orden institucional". En realidad ya había recuperado bastante de esa libertad en los meses que precedieron a su dimisión. En efecto, ya había vuelto a ser él mismo, por así decir, cuando tuvo la ocasión de reencontrarse con el papel en que se sentía a sus anchas - el de tribuno de la "gente" -, y esa ocasión la ofreció la denuncia de que algunos miembros del Senado habían sido sobornados para aprobar una ley laboral. A través de los media, que recogerían día a día sus declaraciones, 
volvió al combate contra los vicios de la vieja política, en cuyas prácticas aparecían ahora involucrados, según las revelaciones sobre los hechos del Senado, no sólo el partido aliado, la UCR, sino también miembros de su propia fuerza. Y el texto de su renuncia, que leyó en el medio de una vasta movilización de apoyo, dejaría al gobierno, indirecta pero claramente, en el lugar de lo viejo "que debe morir”.

"Fundé una fuerza política nueva en la Argentina para, entre otras cosas, cambiar drásticamente la forma de hacer política. Estoy convencido de que estamos ante una crisis terminal en la manera de hacerla, de la relación entre poder político y poder económico, y del vínculo entre la política y la gente [...] Parece paradójico y resulta cada vez más chocante: cuanto más avanzan la pobreza, la desocupación, el escepticismo y la apatía, desde no pocos lugares se responde con dinero negro, compra y venta de leyes, más pragmatismo y más protagonismo para quienes operan en la política como si fuera un negocio para pocos $[\ldots]$ De aquí que esta situación debe enfrentarse con una enorme cuota de coraje y decisión. O se está con lo viejo que debe morir o se lucha por lo nuevo que esta crisis debe ayudar a alumbrar".

$\mathrm{Al}$ margen del desconcertante zig-zag que Alvarez recorrería después de su alejamiento del gobierno y de la crisis en que hundió tanto a la coalición como al Frepaso, esas imágenes relativas al fin de la vieja política, afectada por un cáncer que no podía ser tratado a medias, y la expectativa en el alumbramiento de una nueva política y una nueva república, ya no habían de desaparecer del espacio público. Se las puede encontrar, por ejemplo, en la prédica de Elisa Carrió, que ocupó el lugar de Alvarez en el llamado al regeneracionismo cívico y organizó en torno a su figura una nueva fuerza política, el ARI (Argentinos para un República de Iguales) (7). Pero más allá de cualquier enunciador particular, la representación de una sociedad capturada por mafias, de los políticos profesionales como una de ellas y del nacimiento próximo de una Argentina liberada de ese mal, que algunos remontan a los años de Menem y otros a la última dictadura militar, se convirtió en componente de un discurso extendido, periodístico e intelectual. En esa representación, en que la queja se ligaba a la denuncia de la corrupción - la del "Estado mafioso", según la definición de Carrió, quien muy prontó se halló en la cumbre de las encuestas de opinión -, muchos encontraban la explicación de sus penurias materiales o, quienes no estaban afligidos por ellas pero eran progresistas, la del penoso desempeño de la coalición en que habían puesto sus ilusiones.

De la magnitud del descontento no habría prueba más elocuente que el resultado de las elecciones para diputados y senadores del 14 de octubre del 2001. Las ganó el peronismo, que obtuvo cerca del 30\% en todo el país, pero el hecho central no fue éste, sino las cifras del "voto bronca", denominación con que los analistas agruparon los votos en blanco y nulos. En la ciudad de Buenos 
Aires, este voto de censura a la "clase política" superó las cifras obtenidas por los candidatos de cualquier fuerza, y lo que quedaba de la Alianza apenas retuvo la mitad de los votos que había alcanzado en mayo del año anterior, cuando atrajo casi el 50\% de los sufragios. Aunque el castigo fue rotundo para el gobierno de Fernando de la Rúa, el peronismo también registró pérdidas importantes en varios de sus bastiones electorales, lo que mostraba que la desaprobación y el desencanto no afectaban sólo a los partidos identificados con la Alianza - el radicalismo y el Frepaso. Podría decirse que la sanción electoral del 14 de octubre anticipó la que va a aparecer apenas dos meses después en los cacerolazos, cuando al malestar que sintetizó el "voto bronca" se sumó la irritación por el corralito y la bancarización.

No quisiéramos concluir este parágrafo relativo a la condena de los políticos sin hacer alguna referencia, aunque sea sumaria, al discurso de los opinionmakers mediáticos. No es inoportuno recordar que la crítica a los políticos, vistos como un grupo cuyos intereses son ajenos a las preocupaciones del individuo común - la "gente" - surgió en el ámbito del periodismo de derecha. En efecto, la prédica comenzó en favor del partido del mercado ya a fines de los ochenta y no tuvo propalador más astuto que Bernardo Neustadt, quien conducía en sociedad con Mariano Grondona Tiempo Nuevo, el programa político más influyente de la TV argentina en los primeros años del gobierno de Menem. En el discurso de propaganda de Neustadt el individuo común, simbolizado por una imaginaria "Doña Rosa", era la víctima del estatismo y de las diversas obstrucciones que el partido del Estado oponía a la libertad de los consumidores. Ajenos e indiferentes a los contratiempos y percances de la gente común, aparecían los políticos y, sobre todo, los políticos progresistas, individuos aferrados al pasado. Esta prédica no sólo fue coincidente con los primeros años de la presidencia de Menem, sino que es indisociable de la política que éste llevó a cabo. De hecho, el presidente al igual que Cavallo, el ministro exitoso de entonces, fueron concurrentes regulares del programa que, a su vez, funcionó como agencia de propaganda de la privatización de las empresas públicas y, en general, de todas las medidas destinadas cambiar a la Argentina de acuerdo con una visión encantada, casi mágica del capitalismo neoliberal.

En la segunda mitad de los noventa la estrella de Neustadt cayó, acompañando el desprestigio que experimentaba la administración menemista. De todos modos, el proceso a los políticos ya no abandonó la escena mediática, aunque la desacreditación no sería más monopolio del periodismo de derecha y se alimentaría de acusaciones diferentes a las que había promovido la campaña por el Estado mínimo. No quiero dar a entender que los dirigentes políticos hayan sido apenas el chivo expiatorio de la crisis argentina. Tienen en ella una responsabilidad de primer orden, aunque la corrupción explique sólo parcialmente las inconsecuencias y la ineptitud que han mostrado en el ejercicio del gobierno. La censura que hoy los hostiga no es arbitraria ni puede ser com- 
prendida nada más que como efecto de un discurso orientado a producir "el culpable". Pero el discurso de los opinion makers, que no es portador de convicciones razonadas, sino de "evidencias" que son del orden del todo o nada, contribuyeron a esa simplificación que hizo converger todos los males en el comportamiento moral de los políticos profesionales.

\section{La política en las plazas}

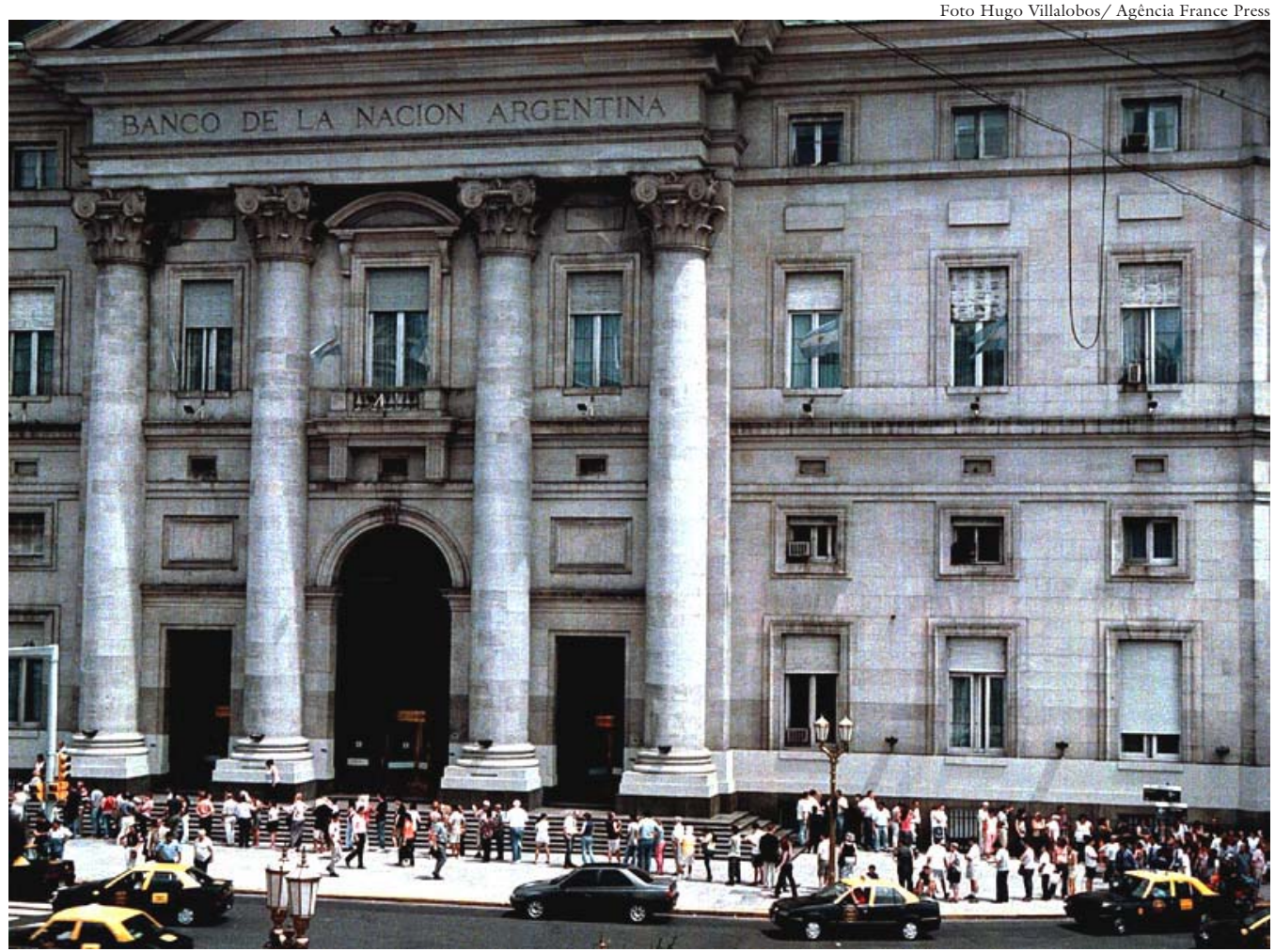

Longa fila de compradores de dólares em frente ao Banco de la Nacion Argentina em 24.1.2002

La protesta de las cacerolas reunió a los diversos segmentos de las clases medias, como quiera se clasifiquen sus clivajes, social o ideológicamente. Es decir, el segmento de los "perdedores" y el de los "ganadores" de la década del noventa, si se quiere registrar diferencias socio-económicas; los segmentos moderados, los progresistas y los de izquierda, si se quiere trazar distinciones aproximadamente ideológicas (8). Un paisaje análogo aparece en las asambleas barriales, que son una de las derivaciones de las movilizaciones de diciembre. Sobre todo si no se considera cada una de las asambleas, sino el conjunto que arman las que hoy se convocan en diferentes días de la semana en esquinas y plazas de la ciudad de Buenos Aires. Unas más numerosas, otras menos, ellas reúnen, en la condición común de vecinos, a ahorristas, comerciantes empobrecidos, amas de casa, profesionales y militantes. No es fácil dar una imagen unificada de lo que ocurre en ellas, más allá de unos pocos rasgos compartidos. 
El igualitarismo es uno de esos rasgos, pues es la sola condición de vecino la que habilita a hablar, expresar reclamos, narrar experiencias y hacer propuestas. Con este igualitarismo va asociado el sentimiento del espacio público recobrado y el de la comunidad en que ningún título que pueda invocarse da más autoridad que otro: en ella pueden hablar todos (9). Las competencias de tipo profesional suelen declararse para ofrecer formas específicas de cooperación con necesidades planteadas en la asamblea. Otro rasgo general, y casi obvio dado lo que hemos dicho hasta aquí, es la recusación de los políticos profesionales. Hay militantes en las reuniones, sobre todo procedentes de los grupos de la izquierda, y en algunas asambleas se admite que puedan hablar proclamando su identidad política, siempre que acepten acatar las decisiones que adopte la mayoría. Un fantasma que los vecinos se preocupan por exorcisar una y otra vez es que sus reuniones no sean manipuladas por «extraños» al cuerpo político que ellos forman. Ese cuerpo, cuyos límites son siempre porosos, se constituye cada vez y en él se integran quienes participaron de la asamblea anterior y los nuevos, los recién llegados. El grado de estructuración de los mitines, así como la existencia y el número de comisiones que prosiguen su actividad entre una reunión y otra, son hechos que varían de una asamblea a otra según el mayor o menor tiempo que lleven funcionando. Una asamblea interbarrial se congrega los domingos en el Parque Centenario y a ella envían sus delegados las asambleas de los barrios.

Más allá de estos aspectos relativos a su funcionamiento y del rechazo al sistema tradicional de partidos, hay una gran diversidad entre las asambleas. Cada una posee una dinámica propia y fija su temario, si bien la comunicación entre ellas, que es cada vez mayor, sobre todo por obra de la asamblea interbarrial y el empeño de los militantes de izquierda, han ido fijando los elementos de una agenda compartida de actividades. Entre éstas, las marchas de los días jueves para repudiar a la Corte Suprema de Justicia y el llamado Cacerolazo Nacional de los días viernes. Fruto del empeño de los militantes es igualmente la comunicación del movimiento de las cacerolas con el movimiento, más articulado, de los piqueteros, como se llama al conjunto de organizaciones que agrupan a los trabajadores desocupados, el otro actor social de la Argentina en crisis.

¿Qué hacer para reemplazar a los políticos cuando se vayan todos? En este punto, las ideas y también las fantasías son variadas: desde la propuesta de formar partidos nuevos, surgidos de las asambleas, a la de poner en práctica mecanismos de democracia directa, sin delegación. El sueño de la sociedad transparente, que prolongue y amplifique la comunidad que es la asamblea misma, y del buen gobierno como su coronación, sobrevuela estas discusiones. En algunas asambleas se ha votado a favor de la rebeldía fiscal - no pagar más impuestos -, para exigir, a continuación, que mejoren los servicios que se pagan con esos tributos. Cuando las asambleas deliberan en torno a estos proyectos se percibe con más claridad que nunca el sentimiento de poder que dejó la experiencia de 
la movilización que puso fin al gobierno de Fernando de la Rúa. El sentimiento se refuerza ante la comprobación del temor que experimentan los políticos y el gobierno presidido por Duhalde ante el veredicto de los cacerolazos. Pero en las asambleas aparece también otra agenda, de carácter vecinalista, que recoge urgencias locales y propuestas para encarar las penurias del empobrecimiento con respuestas cooperativas. En fin, si esto es lo que podemos saber, ¿qué es lo que podemos esperar? Ciertamente, resulta imposible aventurar hoy qué curso tomará finalmente este proceso. La activación de la preocupación cívica que se refleja en las asambleas puede producir, como muchos de sus participantes esperan, una revigorización de la precaria democracia argentina. Puede animar también nuevas fuerzas políticas y nuevas formas de participación en el gobierno de la ciudad. Pero, si se entregan a una radicalización sectaria y al demonio de la purificación, que suele ser su complemento, para perseguir la sociedad que sea el Bien, liberada de toda injusticia, solo conseguirán aislarse y pasar a formar parte del proceso de disgregación que amenaza al país.

Mientras tanto, la crisis sigue su trabajo corrosivo. El gobierno de Duhalde se muestra cada día más frágil frente a la presión abierta de lobbies poderosos y al hostigamiento de los caudillos provinciales del peronismo. El llamado Diálogo Argentino, convocado por el presidente con el auspicio de la Iglesia Católica y la asistencia técnica del Programa de las Naciones Unidas para el Desarrollo, sólo ha producido, después de un mes y medio de deliberaciones con prácticamente todos los actores posibles, sociales y políticos, un documento en que llama a anteponer el bien común a todo interés individual o corporativo. Todo indica, pues, que las cuestiones principales aún están por resolverse.

Buenos Aires, 28 de fevereiro de 2001

Notas

1 Susana Viau, "El futuro es un cristal turbio", Página 12, 10/2/02.

2 Clarin, 20/12/01.

3 Susana Torrado, Estructura social de la Argentina: 1945-1983, Buenos Aires, Ediciones de la Flor, 1992.

4 Gino Germani, Estructura social de la Argentina. Análisis estadístico (1956), Buenos Aires, Solar, 1987, p. 221-225.

5 Susana Torrado, op. cit.

6 Maristella Svampa, Los que ganaron. La vida privada en los countries y barrios privados, Buenos Aires, Biblos, 2001, p.33-4.

7 Surgida de las filas del partido radical, Elisa Carrió ha instalado su figura en la opinión pública por medio de denuncias a la corrupción de todo el sistema político, y el movimiento que encabeza, como en buena medida ocurría con el Frepaso, es poco más que un conjunto de círculos e individuos agrupados en torno a ella. 
8 Según un sondeo de la encuestadora Analogías ( 1.500 casos en todo el país, entre el 12 y el 18 de febrero) la mayoría de quienes asisten a los cacerolazos son personas de nivel socio-económico alto que han quedado atrapadas en el corralito. No es fácil evaluar este dato, consignado por el diario Clarín (24/2/02), al ignorar cómo construye sus categorías la mencionada encuestadora.

9 «Los que participamos de las reuniones barriales recuperamos el espacio público y la palabra. Hay hombres y mujeres de 60 años o más que participan en una asamblea por primera vez. Ellos tienen muchas cosas que decir, broncas para sacar afuera, sentimientos desprolijos que salen a borbotones, miedos muy justificados». Declaración de un vecino asambleísta, en Luis Grus, «Democracia al aire libre», Revista. La Nación, 10/2/02.

Carlos Altamirano é professor na Faculdade de Filosofía e Letras da Universidade de Buenos Aires e da Universidade Nacional de Quilmes. Entre seus livros recentes se encontram: Ensayos argentinos: de Sarmiento a la vanguardia (1997), em colaboração com Beatriz Sarlo; Frondizi: el hombre de ideas como político (1998); Peronismo y cultura de izquierda (2001) e Bajo el signo de las masa - 1943-1973 (2001). É pesquisador do Consejo Nacional de Investigaciones Científicas e Técnicas (CONICET) e se ocupa de história das idéias. 